Supporting Information for:

\title{
Plasmonic Hot Electron Solar Cells: The Effect of Nanoparticle Size on Quantum Efficiency
}

Philipp Reineck ${ }^{+}$, Delia Brick ${ }^{+}$, Paul Mulvaney ${ }^{\S}$ and Udo Bach ${ }^{+\notin \#}$

${ }^{+}$Department of Materials Engineering, Monash University Clayton, VIC 3800, Australia

$\S$ School of Chemistry \& Bio21 Institute University of Melbourne Parkville, VIC 3010, Australia

\& Commonwealth Scientific and Industrial Research Organization, Manufacturing Flagship, Clayton, Victoria 3168, Australia

\# Melbourne Centre for Nanofabrication, 151 Wellington Road, Clayton, VIC 3168, Australia

\section{3 nm Au Nanoparticle Synthesis}

All chemicals were used as received. Au NP synthesis: $0.5 \mathrm{~mL}$ of an aqueous $\mathrm{HAuCl}_{4}$ (Sigma-Aldrich, $99.999 \%$ purity) solution $(0.1 \mathrm{M})$ was added to $99.5 \mathrm{~mL}$ of DI water. The solution was brought to boil and $5 \mathrm{~mL}$ of a $1 \mathrm{wt}$. \% aqueous solution of sodium citrate tribasic dihydrate (Sigma-Aldrich, $\geq 99.0 \%$ purity) was added under vigorous stirring. The solution was allowed to boil for 20 minutes and then allowed to cool to room temperature overnight. 


\section{Nanoparticle Self-assembly: Density Variation}

A

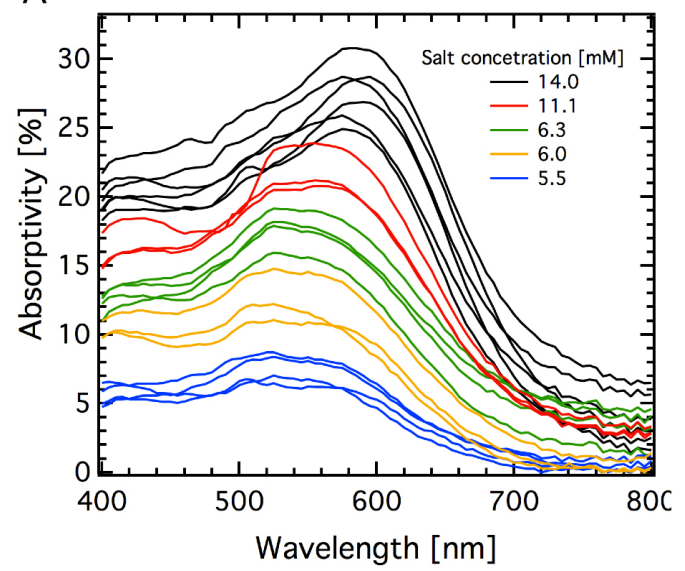

B

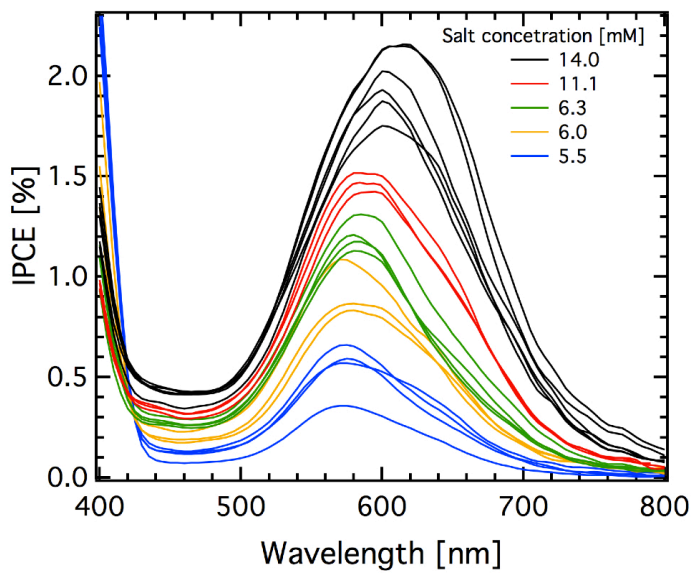

Figure S1. Absorptivity and IPCE spectra for individual solar cells. Absorption spectra were obtained before the spin-coating of the hole-transport material spiro-OMeTAD and the absorption of the dense $\mathrm{TiO}_{2}$ was subtracted from the raw data, leading to a decrease in absorptivity below $400 \mathrm{~nm}$. The $\mathrm{NaCl}$ concentration was kept constant at $[\mathrm{NaCl}]=3.6 \mathrm{mM}$ and the $\mathrm{HCl}$ concentration was varied between $10.4 \mathrm{mM}$ and $1.9 \mathrm{mM}$. The self-assembly time was 10 minutes in all cases. All substrates were rinsed with deionized water after the selfassembly to remove unadsorbed NPs from the substrate.

A
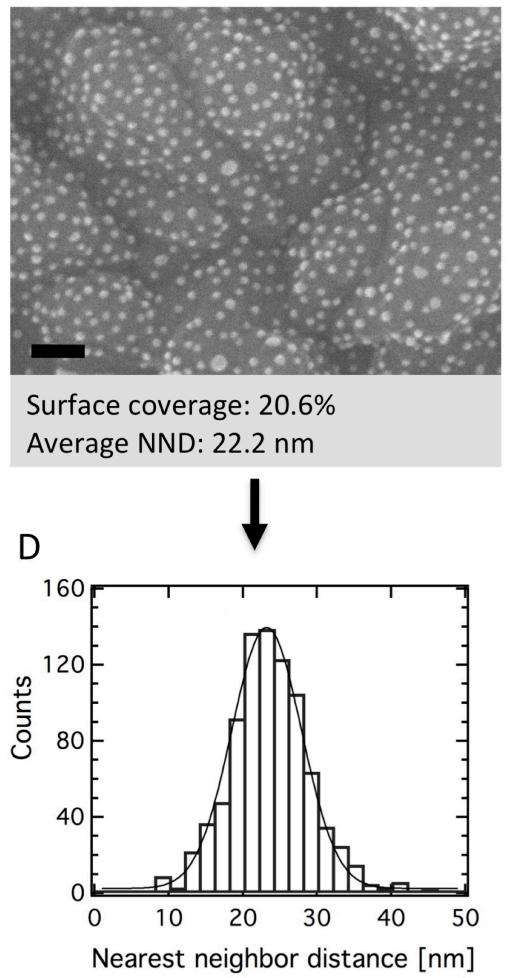

B

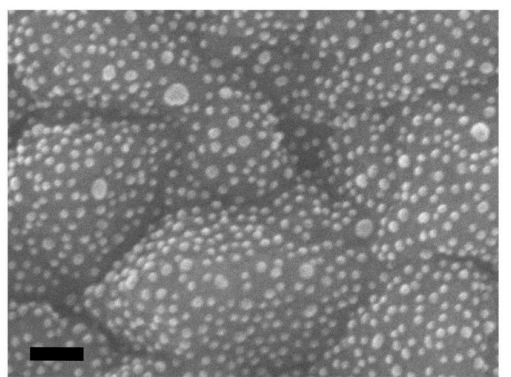

Surface coverage: $25.4 \%$ Average NND: $20.1 \mathrm{~nm}$

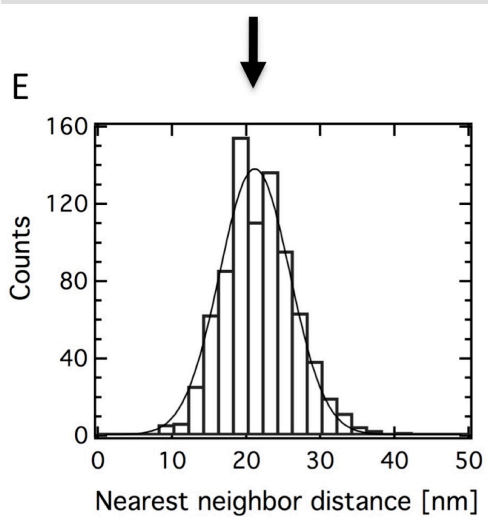

C

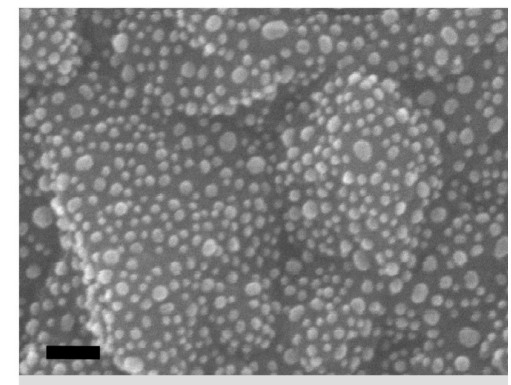

Surface coverage: $31.6 \%$ Average NND: $18.9 \mathrm{~nm}$

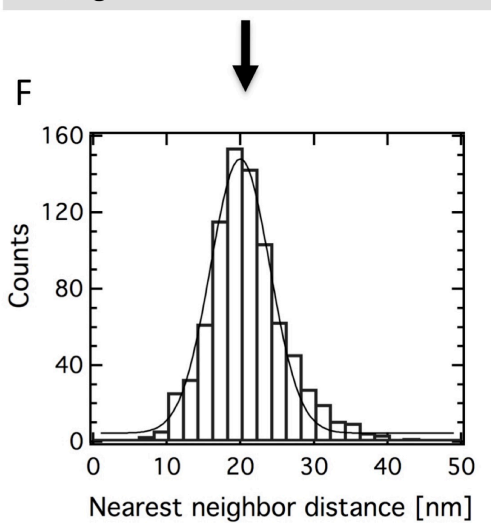

Figure S2. SEM images (A-C) and nearest neighbor distance distributions (D-F) for three different nanoparticle densities of $13 \mathrm{~nm}$ Au NPs on the solar cell substrate. All 
scale bars: $100 \mathrm{~nm}$. A Gaussian fit is shown for the nearest neighbor distance (NND) distributions and the average NND given represents the center of this distribution. NNDs represent the surface-to-surface distance between nearest neighbor particles.

\begin{tabular}{|c|c|c|c|}
\hline $\begin{array}{l}\text { SEM } \\
\text { image }\end{array}$ & $\begin{array}{l}\text { Debye length } \\
{[\mathrm{nm}]}\end{array}$ & $\begin{array}{l}\text { Calculated } \\
\text { NND [nm] }\end{array}$ & $\begin{array}{l}\text { Experimental } \\
\text { NND [nm] }\end{array}$ \\
\hline A & 4.1 & 21.2 & 22.2 \\
\hline B & 3.8 & 20.7 & 20.1 \\
\hline C & 2.6 & 18.1 & 18.9 \\
\hline
\end{tabular}

Table S1. Comparison of calculated and measured nearest neighbor distances. NND values were calculated assuming a minimum surface-to-surface particle separation of twice the Debye length $\lambda_{\mathrm{D}}$ and an average particle diameter $\mathrm{D}=13 \mathrm{~nm}$ according to: $\mathrm{NND}=2 \lambda_{\mathrm{D}}+\mathrm{D}$.

\section{Self-Assembly Process}

Fluorine doped tin oxide coated glass, 1.8mm thickness (Asahi Glass Fabritech Co., Japan), was washed by sonication in ethanol for at least 30 minutes followed by rinsing the substrates with deionized water and ethanol. The spray pyrolysis of $\mathrm{TiO}_{2}$ was carried out as described elsewhere. ${ }^{1}$ Residual organic material was removed before the self-assembly by a UV-ozone treatment using a SAMCO UV-1 (Samco Inc., Japan) for 10 minutes at an oxygen flow rate of 4 liters per minute. $13 \mathrm{~nm} \mathrm{Au}$ NPs were synthesized using the Turkevich method. ${ }^{2}$ Briefly, $0.5 \mathrm{ml}$ of an aqueous $\mathrm{HAuCl}_{4}$ (Sigma-Aldrich, $99.999 \%$ purity) solution (0.1M) was added to $99.5 \mathrm{ml}$ of DI water. The solution was brought to boil and $5 \mathrm{ml}$ of a $1 \mathrm{wt} \%$ aqueous solution of sodium citrate tribasic dihydrate (Sigma-Aldrich, $\geq 99.0 \%$ purity) was added under vigorous stirring. The solution was allowed to boil for 20 minutes and then cooled to room temperature overnight. All other particle sizes were purchased as aqueous colloidal NP solutions from Ted Pella, USA. All NP solutions were concentrated to $50-100 \mathrm{nM}$ particle concentration via centrifugation.

For the NP density variation, salt concentrations given in the caption of Figure S1 were set through the addition of aqueous solutions of $\mathrm{NaCl}$ and $\mathrm{HCl}$ respectively. For the self-assembly of nanoparticles of different sized, the following concentrations were used: 


\begin{tabular}{|l|l|l|}
\hline NP size & {$[\mathrm{HCl}]$ in $\mathrm{mM}$} & {$[\mathrm{NaCl}]$ in $\mathrm{mM}$} \\
\hline $5 \mathrm{~nm}$ & 10.5 & 3.5 \\
\hline $10 \mathrm{~nm}$ & 8.4 & 3.6 \\
\hline $13 \mathrm{~nm}$ & 8.4 & 3.6 \\
\hline $20 \mathrm{~nm}$ & 5.6 & 3.1 \\
\hline $40 \mathrm{~nm}$ & 3.8 & 1.9 \\
\hline
\end{tabular}

Table S2. Concentrations in the nanoparticle solutions used for the self-assembly of the different particle sizes.

\section{Solar Cell Fabrication}

The NP SAMs on $\mathrm{TiO}_{2}$-coated FTO glass were heated to $500^{\circ} \mathrm{C}$ for 20 minutes using a hotplate (Harry Gestigkeit $\mathrm{GmbH}$, Germany). Then $36 \mathrm{mg}$ of spiro-OMeTAD (Merck AG, Germany) was dissolved in $400 \mu \mathrm{l}$ chlorobenzene (Sigma-Aldrich, anhydrous, 99.8\%). $7 \mu 1$ 4-tert-butylpyridine (Sigma-Aldrich, $\geq 98.0 \%$ purity) and 15 $\mu 1$ of $17 \mathrm{mg}$ bis(trifluoromethane)sulfonimide lithium salt (Sigma-Aldrich, 98.95\% purity) dissolved in $100 \mu \mathrm{l}$ acetonitrile (anhydrous, 99.8\% purity) were added thereafter. Ca. $60 \mu 1$ of this solution was deposited onto a $2 \times 2 \mathrm{~cm}$ substrate using a spin coater (WS-400BZ-6NPP/Lite, Laurell Technologies, USA) @ 2000 rpm. A 30 $\mathrm{nm}$ thick Au film was evaporated on top at a rate between 0.5 and $1 \AA$ per second. 

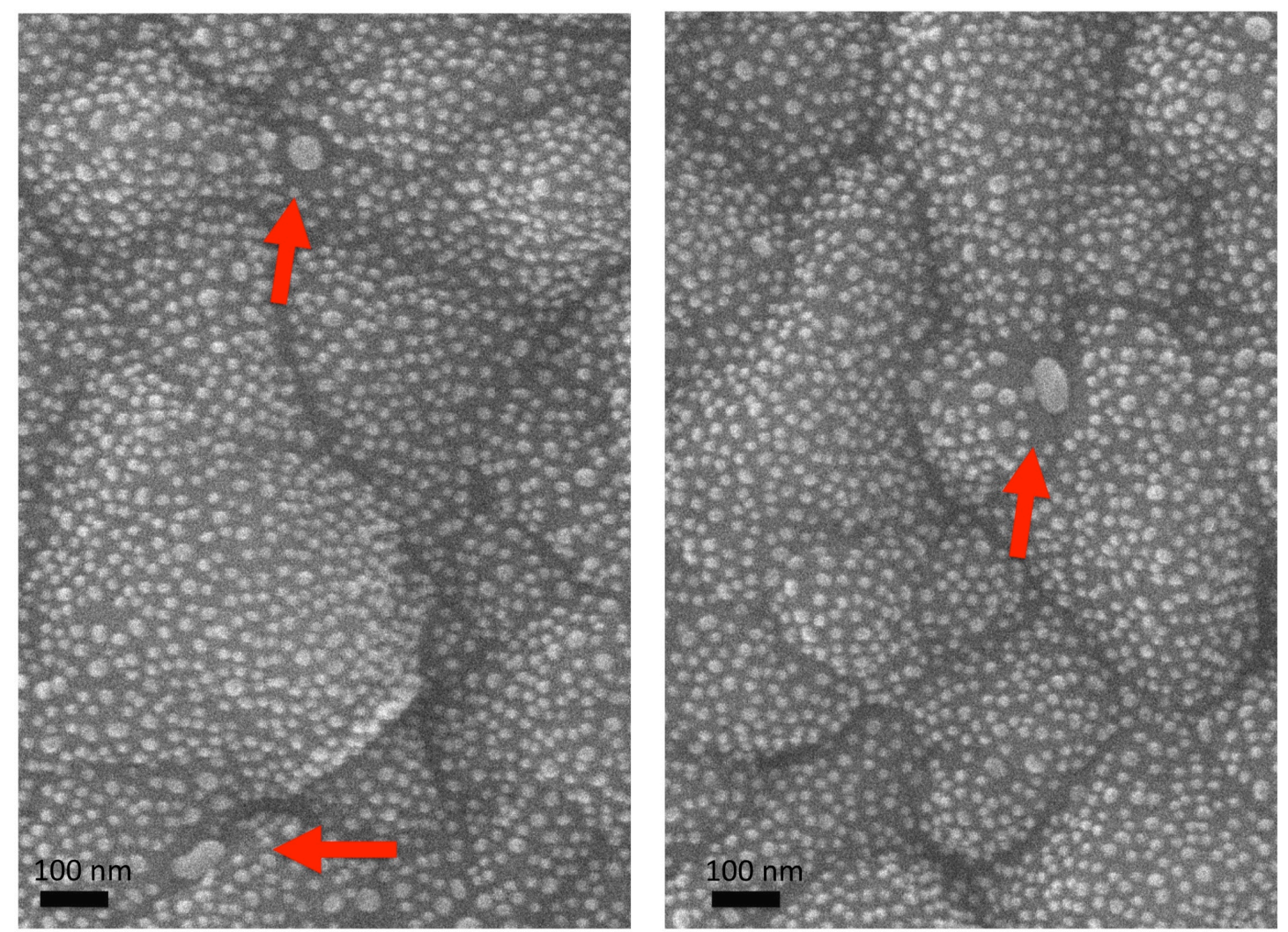

Figure S3. SEM images of high-density $13 \mathrm{Au}$ NP monolayers on a $\mathrm{TiO}_{2}$-coated substrate after the heat treatment $\left(500^{\circ} \mathrm{C}, 20 \mathrm{~min}\right)$ using a heatgun. Red arrows indicate locations where particles have likely fused during the heating step to form larger particles.

A
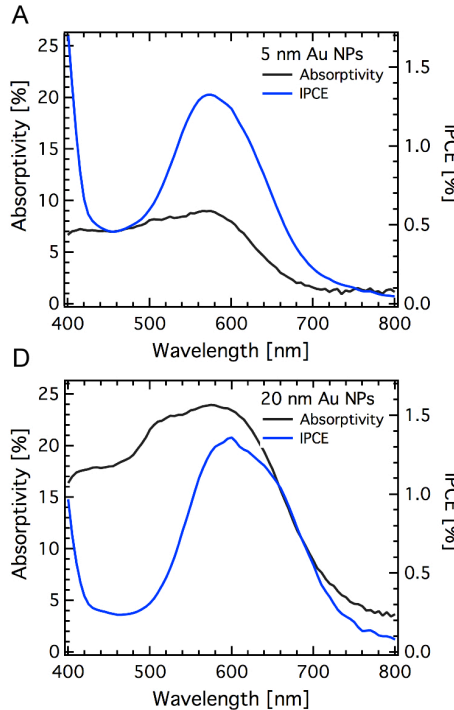

B

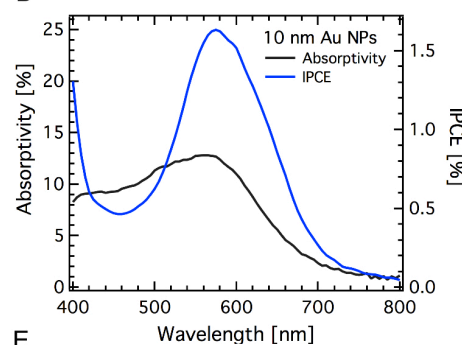

$\mathrm{E}$

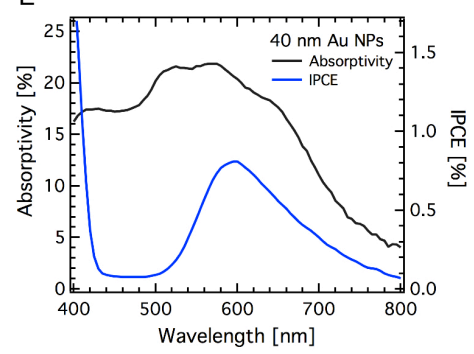

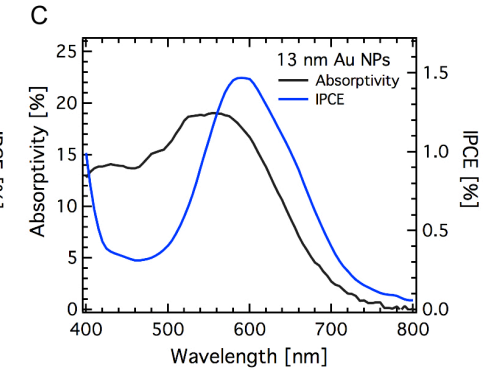

$\frac{m}{2}$

Figure S4. Typical absorptivity and IPCE spectra for all particle sizes investigated: A: $5 \mathrm{~nm}$, B: $10 \mathrm{~nm}, C: 13 \mathrm{~nm}, \mathrm{D}: 20 \mathrm{~nm}, \mathrm{E}: 40 \mathrm{~nm}$. Absorptivity and IPCE scales are identical in all graphs to enable a direct comparison. 

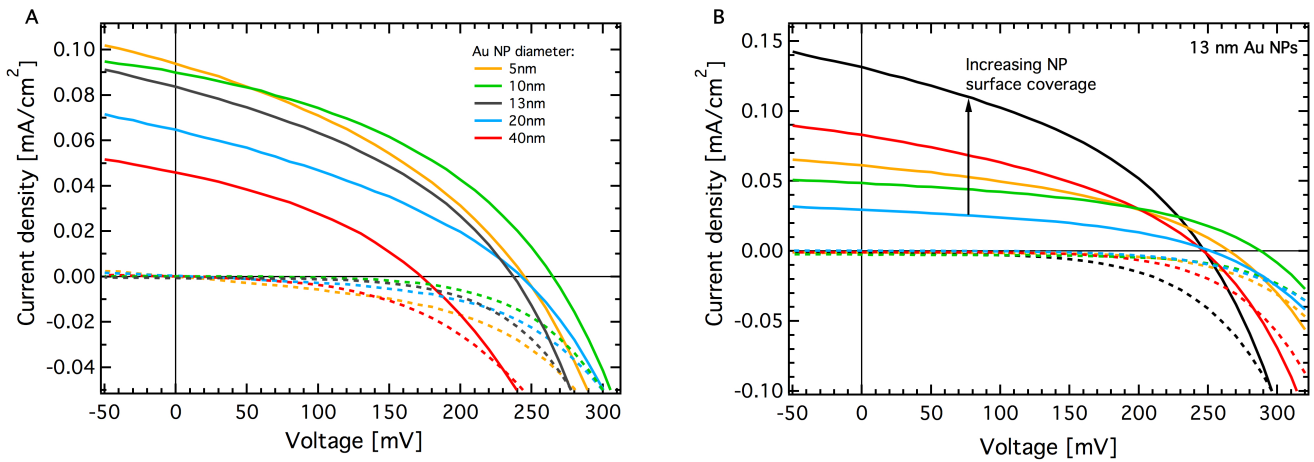

Figure S5. Typical current-voltage characteristics of the Au NP solar cells investigated. A: The generated photocurrents increase with decreasing particle size. B: Photocurrents generated by $13 \mathrm{~nm}$ Au NPs increase with increasing nanoparticle surface coverage as indicated by the arrow.
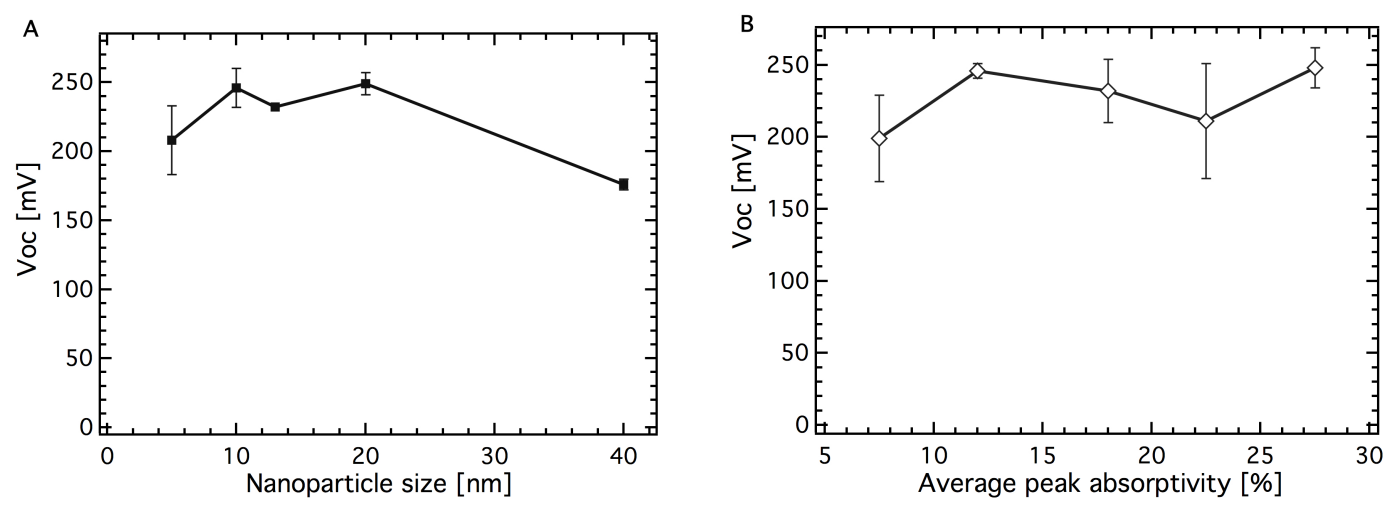

Figure S6. Average open circuit voltages of the cells as a function of nanoparticle size (A) and average peak absorptivity (B).

\section{Solar Cell Testing}

The spectral response (IPCE) was measured using a $150 \mathrm{~W}$ xenon lamp (Oriel Instruments, USA) fitted with a monochromator (Cornerstone 260, Newport Instruments, USA) as the light source. IPCE photocurrents were recorded under shortcircuit conditions using a Keithley 2400 source meter. The monochromatic photon flux was quantified by means of a calibrated silicon photodiode (Peccell Technologies, Japan).

IV testing: A sun simulator (Oriel Instruments, USA) fitted with a filtered 1,000 W xenon lamp was used to provide simulated solar irradiation (air-mass 1.5, 1,000 W 
m-2). Current-voltage curves were recorded using a Keithley 2400 source meter (Keithley Instruments, USA) from which the open circuit voltages were determined. The output of the light source was adjusted using a calibrated silicon photodiode (Peccell Technologies, Japan).

\section{Calculations for Figure 5}

\section{Constants:}

$\mathrm{q}=1.60217657 \times 10^{-19} \mathrm{C}$ (elementary charge);

$\mathrm{h}=6.62606957 \times 10^{-34} \mathrm{~J} \mathrm{sec} \quad$ (Planck's constant)

$\mathrm{c}=299792458 \mathrm{~m} \mathrm{sec}^{-1}$ (speed of light)

$\lambda=590 \times 10^{-9} \mathrm{~m}$ (center wavelength of the LED excitation)

\section{Measured quantities:}

$\mathrm{J}_{\mathrm{SC}}$ : current density under short circuit conditions in ampere per $\mathrm{cm}^{2}$

$\mathrm{P}_{\mathrm{IN}}$ : irradiance (power of light incident on the substrate surface) in watts per $\mathrm{cm}^{2}$

Abs : fraction of incident light absorbed by the NP monolayer on the substrate at the excitation wavelength of $590 \mathrm{~nm}$

\section{Calculated quantities:}

$\mathbf{N}_{\mathrm{e}-\text { : }}$ number of electrons generated by the solar cell per second per $\mathrm{cm}^{2}$

$$
N_{e-}=\frac{J_{S C}}{q}
$$

$\mathbf{N}_{\text {ph }}$ : number of photons absorbed by the NP monolayer per second per $\mathrm{cm}^{2}$

$$
N_{p h}=\frac{P_{i n}}{h c / \lambda} A b s
$$

The resulting values were subsequently expressed and plotted in $\mu$ s and $\mu \mathrm{m}^{2}$ (instead of seconds and $\mathrm{cm}^{2}$ ) by multiplying all values by $10^{-14}$.

\section{References}

(1) Kavan, L.; Grätzel, M. Highly Efficient Semiconducting TiO2 Photoelectrodes Prepared by Aerosol Pyrolysis. Electrochim. Acta 1995, 40 (5), 643-652.

(2) Enustun, B. V; Turkevich, J. Coagulation of Colloidal Gold. J. Am. Chem. Soc. 1963, 85 (21), 3317-3328. 